\title{
The effect of basal channels on oceanic ice-shelf melting
}

\author{
Thomas Millgate, ${ }^{1,2}$ Paul R. Holland, ${ }^{1}$ Adrian Jenkins, ${ }^{1}$ and Helen L. Johnson ${ }^{2}$ \\ Received 3 September 2013; revised 7 November 2013; accepted 15 November 2013; published 18 December 2013.
}

[1] The presence of ice-shelf basal channels has been noted in a number of Antarctic and Greenland ice shelves, but their impact on basal melting is not fully understood. Here we use the Massachusetts Institute of Technology general circulation model to investigate the effect of ice-shelf basal channels on oceanic melt rate for an idealized ice shelf resembling the floating tongue of Petermann Glacier in Greenland. The introduction of basal channels prevents the formation of a single geostrophically balanced boundary current; instead the flow is diverted up the right-hand (Coriolis-favored) side of each channel, with a return flow in the opposite direction on the left-hand side. As the prescribed number of basal channels is increased the mean basal melt rate decreases, in agreement with previous studies. For a small number of relatively wide channels the subice flow is found to be a largely geostrophic horizontal circulation. The reduction in melt rate is then caused by an increase in the relative contribution of weakly melting channel crests and keels. For a larger number of relatively narrow channels, the subice flow changes to a vertical overturning circulation. This change in circulation results in a weaker sensitivity of melt rates to channel size. The transition between the two regimes is governed by the Rossby radius of deformation. Our results explain why basal channels play an important role in regulating basal melting, increasing the stability of ice shelves.

Citation: Millgate, T., P. R. Holland, A. Jenkins, and H. L. Johnson (2013), The effect of basal channels on oceanic ice-shelf melting, J. Geophys. Res. Oceans, 118, 6951-6964, doi:10.1002/2013JC009402.

\section{Introduction}

[2] The Greenland and Antarctic ice sheets contributed $0.59 \mathrm{~mm} / \mathrm{yr}$ to sea level rise between 1992 and 2011 [Shepherd et al., 2012]. The largest contribution to this is from the acceleration and thinning of the ice streams, which is thought to be a consequence of enhanced oceanic melting of their floating ice shelves [Shepherd et al., 2004; Holland et al., 2008a]. This implies that being able to predict the stability of ice shelves, and understand the ice-ocean interactions at their base, is an important step in being able to predict the stability of the Greenland and Antarctic ice sheets.

[3] Greenland's outlet glaciers terminate in long narrow fjords as either a tidewater glacier or (less often) a floating ice tongue. Within the fjords there is a surface layer of Polar Water overlaying warmer modified Atlantic Water, with the Atlantic Water generally being warmer in fjords further south [Straneo et al., 2012]. The glaciers feeding fjords with warmer Atlantic Water tend to terminate as tidewater glaciers without ice shelves. Various studies have

\footnotetext{
${ }^{1}$ British Antarctic Survey, Cambridge, UK.

${ }^{2}$ Department of Earth Sciences, University of Oxford, Oxford, UK.

Corresponding author: T. Millgate, British Antarctic Survey, High Cross, Madingley Road, Cambridge CB3 0ET, UK. (tmilg@bas.ac.uk)

(C)2013. American Geophysical Union. All Rights Reserved. 2169-9275/13/10.1002/2013JC009402
}

linked the retreat of Greenland's glaciers to the warming of subsurface waters [Holland et al., 2008a; Nick et al., 2009; Christoffersen et al., 2011].

[4] Petermann Glacier $\left(81^{\circ} \mathrm{N}, 61^{\circ} \mathrm{W}\right)$ is a major outlet glacier in northern Greenland, draining about $6 \%$ of the Greenland Ice Sheet area, and is one of four Greenland glaciers that are grounded deeper than $500 \mathrm{~m}$ below sea level [Falkner et al., 2011]. Prior to 2010, Petermann Glacier terminated in a $70 \mathrm{~km}$ long ice shelf confined by Petermann Fjord [Rignot and Steffen, 2008; Johnson et al., 2011]. The ice shelf had been relatively stable over the last century in terms of both ice velocity and ice-shelf extent [Higgins, 1991; Falkner et al., 2011], potentially due in part to the modified Atlantic water layer being cooler than that found in more southerly fjords around Greenland [Straneo et al., 2012]. Since 2010, two large calving events have removed an area of approximately $275 \mathrm{~km}^{2}$ from Petermann Ice Shelf, reducing the ice shelf to about $40 \mathrm{~km}$ long [Falkner et al., 2011].

[5] Channels carved into the base of ice shelves (basal channels) have been recorded in several ice shelves around both Greenland and Antarctica, typically those with a strong oceanic thermal driving. In Greenland, Rignot and Steffen [2008] found that the floating tongue of Petermann Glacier has pronounced channels aligned in the direction of ice flow (Figure 1), while Motyka et al. [2011] revealed the existence of a large channel in the base of Jacobshavn Isbræ's ice tongue before its retreat from 1998 onward. Basal channels have also been found under the ice shelf of Antarctica's 


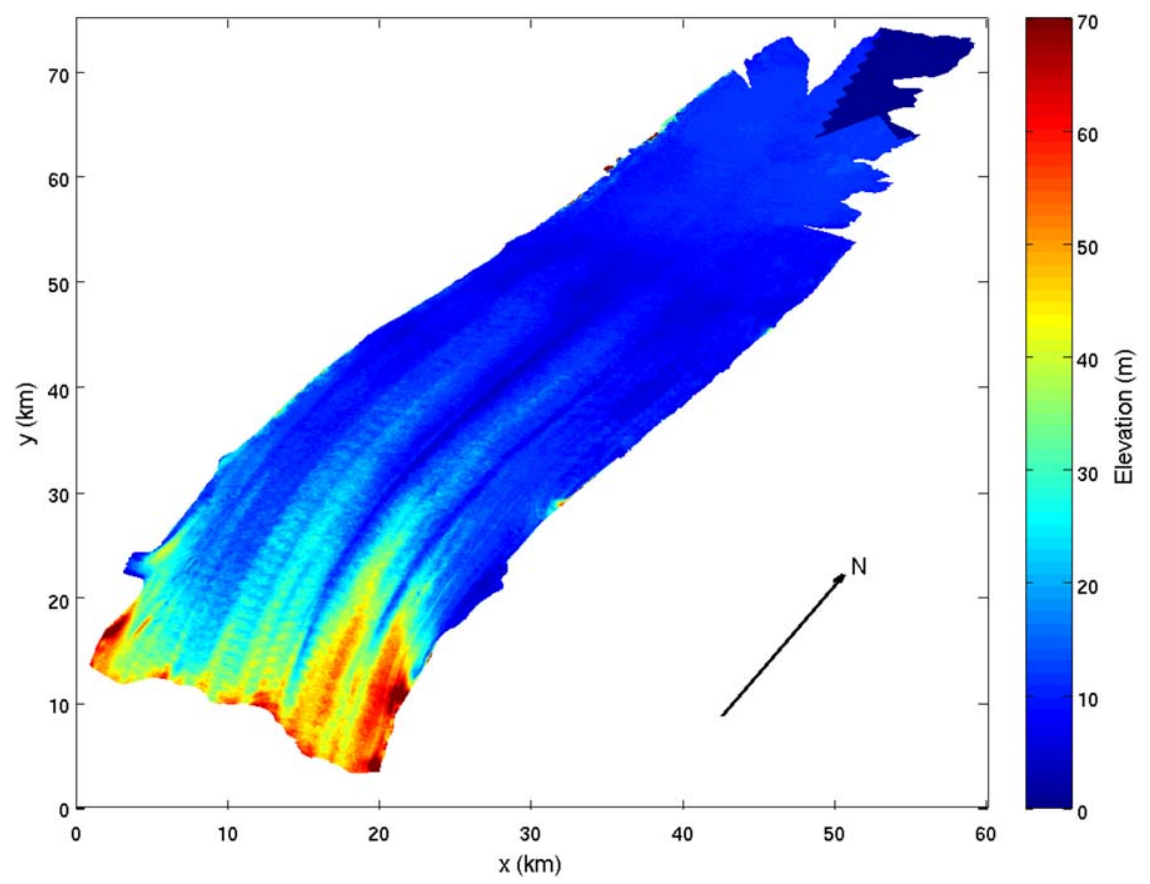

Figure 1. ASTER DEM of Petermann Ice Tongue, North West Greenland $\left(81^{\circ} \mathrm{N}, 61^{\circ} \mathrm{W}\right)$, in polar stereographic projection. Basal channels are seen as surface features because the ice shelf is floating.

Pine Island Glacier [Payne et al., 2007; Mankoff et al., 2012; Vaughan et al., 2012; Dutrieux et al., 2013].

[6] Both Payne et al. [2007] and Mankoff et al. [2012] found that the presence of these channels had an impact on the oceanography within the subice-shelf cavity, directing the meltwater along the channels from the inner cavity toward the ice front. Payne et al. [2007] suggested this would lead to enhanced melting within the channels and channel deepening. Instead, Dutrieux et al. [2013] show that these channels are carved by ocean melting near the grounding line, and then diminished downstream by melting at the keels between channels. Payne et al. [2007] found that the channeling of meltwater plumes resulted in enough residual heat reaching the sea surface at the ice front to cause the formation of small polynyas. Mankoff et al. [2012] noted that basal channels are common on ice shelves, but are only prominent on those which undergo intense basal melting.

[7] There are several proposed mechanisms for the formation of basal channels. Gladish et al. [2012] found that undulations in ice thickness at the grounding line are amplified by oceanic melting to form longitudinal channels, whilst a channels failed to form with a smooth (constant) grounding line thickness. Le Brocq et al. [2013] suggest that ice-shelf channels can be formed by subglacial water crossing the grounding lines in a channelized manner, entraining warmer ocean water, inducing large localized melt rates which form small basal channels which are enhanced by oceanic melting. Sergienko [2013] has shown that in the presence of lateral shear, basal channel can spontaneously appear, even without undulations at the grounding line. However at Petermann Glacier we expect the lateral shear to be low, and undulations have been shown to be high at the grounding line [Rignot and Steffen, 2008].
[8] The question of the overall importance of basal channels to ice-shelf stability remains open. Rignot and Steffen [2008] suggested that there is an increase in mechanical weakness at the crest of channels, where the ice is thinnest. Vaughan et al. [2012] showed that the settling of crests and keels toward hydrostatic equilibrium is responsible for fracturing the ice, weakening it further.

[9] In contrast, Gladish et al. [2012] formulated a coupled ice shelf-ocean plume model, finding that basal channels actually increased the stability of ice shelves by preventing the development of focussed high melt rates which melted completely through the ice shelf in the absence of channels. Moreover, the melting of the ice shelf decreased monotonically with an increasing number of smaller channels. The reduced ocean physics in the simple model of Gladish et al. [2012], however, precluded an investigation of the physical mechanism behind this sensitivity. In this study, we use the full three-dimensional Massachusetts Institute of Technology general circulation model (MITgcm) to further investigate the impact of basal channels on ice-ocean interactions and thus the stability of ice shelves.

\section{Methods and Modeling}

\subsection{The Domain}

[10] To investigate the impact of basal channels we consider an idealized Greenland ice shelf constrained within a long, narrow fjord. The geometry is chosen to broadly match the features of Petermann Glacier and fjord, before the 2010 calving event [Rignot and Steffen, 2008; Johnson et al., 2011]. The domain is a north-south orientated rectangle, $100 \mathrm{~km}$ long, $20 \mathrm{~km}$ wide, and $900 \mathrm{~m}$ deep. Free-slip boundaries on the southern, eastern, and western edges of 


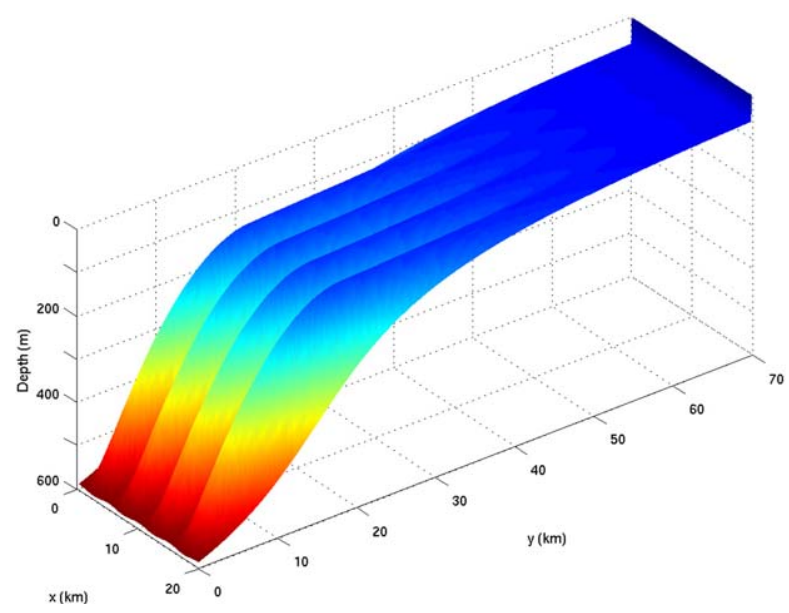

Figure 2. Ice shelf geometry with four channels.

the domain represent the glacier's grounding line and the fjord walls, respectively.

[11] The ice shelf extends $70 \mathrm{~km}$ from the southern boundary, spans the width of the domain, and thins from a $600 \mathrm{~m}$ draft at the grounding line to $60 \mathrm{~m}$ at the ice front. Channels, which run parallel to the flow direction and are sinusoidal in the cross-shelf direction, are introduced across the entire width of the ice-shelf base (Figure 2). The ice draft under the channel crests thins quadratically at first in the along-stream direction, before thinning linearly to the ice front,

$$
d_{c}=\left\{\begin{array}{cl}
a y^{2}+b y+c & \text { if } y \leq 20 \mathrm{~km} \\
-116+0.8 y & \text { if } y>20 \mathrm{~km}
\end{array}\right.
$$

where $d_{c}$ is the channel crest draft $(\mathrm{m}), y$ is distance from southern boundary $(\mathrm{km}), a=-1.21, \quad b=49.2$, and $c=-600$. This profile was chosen to approximately reproduce the features seen in a Digital Elevation Map (DEM) created from the Advanced Spacebourne Thermal Emission and Reflection Radiometer (ASTER) instrument aboard the Terra satellite (Figure 1) and in Rignot and Steffen [2008]. The along-shelf shape of the channel keels was based on a tangent function,

$$
d_{k}=k_{a}\left(\arctan \left(k_{b}\left(y-k_{c}\right)\right)\right)-k_{d}
$$

where $d_{k}$ is the channel keel draft $(\mathrm{m}), k_{a}=229.8041$, $k_{b}=0.09, k_{c}=15$, and $k_{d}=375.164$. For a case of no basal channels, the ice profile is taken as the mean profile of the crest and keel, ensuring that the mean ice draft is consistent for all model runs. Nine different ice-shelf topographies were considered in this study, with the number of channels varying from 0 to 8 . The domain size remains fixed in each configuration, implying a decrease in channel width and an increase in the steepness of channel sides as the number of channels increases.

[12] In 2009, Johnson et al. [2011] conducted a CTD section across Petermann Fjord between the ice front and fjord-mouth sill and found a cold, fresh water mass overlaying a warmer, saltier layer of modified Atlantic Water. The initial temperature and salinity profiles in the model were based on this observational data. In the top $100 \mathrm{~m}$ of the water column the temperature profile increases linearly with depth from $-1.7^{\circ} \mathrm{C}$ at the surface to $0.3^{\circ} \mathrm{C}$, and salinity increases from 30 to 34.8 . The water column is homogenous below $100 \mathrm{~m}$. These profiles were also used for restoring on the northern boundary with a $24 \mathrm{~h}$ restoring timescale.

\subsection{The Model}

[13] The MIT general circulation model (MITgcm) [Marshall et al., 1997a, 1997b] is used to model the seawater-filled cavity beneath a steady ice shelf. The MITgcm "shelfice" package parameterizes melting at the base of a stable floating ice shelf [Losch, 2008] based upon the three equations from Hellmer and Olbers [1989]:

$$
\begin{gathered}
\rho_{o} c_{o} \gamma_{T}\left(T-T_{b}\right)=m \rho_{o} L+\rho_{I} c_{I} \kappa_{I}\left(\frac{T_{b}-T_{I}}{H_{I}}\right) \\
\gamma_{S}\left(S-S_{b}\right)=m S_{b} \\
T_{b}=a S_{b}+b+c d
\end{gathered}
$$

where $m$ is the basal melt rate; $c_{o}=3994 \mathrm{~J} \mathrm{~kg}^{-1 \circ} \mathrm{C}^{-1}$ and $c_{I}=2000 \mathrm{~J} \mathrm{~kg}^{-1}{ }^{\circ} \mathrm{C}^{-1}$ are the specific heat capacity of water and ice, respectively; $L=3.34 \times 10^{5} \mathrm{~J} \mathrm{~kg}^{-1}$ is the latent heat of ice fusion; $\rho_{o}$ is the density of the ocean surface layer; $\rho_{I}=917 \mathrm{~kg} \mathrm{~m}^{-3}$ is the density of the ice shelf; $\kappa_{I}=1.541 \times 10^{-6} \mathrm{~m}^{2} \mathrm{~s}^{-1}$ is the molecular thermal conductivity of the ice shelf; $H_{I}$ is the ice-shelf thickness; $T$ and $S$ are the temperature and salinity of the mixed layer; $T_{b}$ and $S_{b}$ are the temperature and salinity at the ice-ocean interface; $T_{I}=-20^{\circ} \mathrm{C}$ is the core temperature of the ice shelf; $d$ is ice draft; $a=-0.0575^{\circ} \mathrm{Cpsu}^{-1}, b=0.0901^{\circ} \mathrm{C}$, and $c=7.61 \times 10^{-4 \circ} \mathrm{CPa}^{-1}$. The "shelfice" package applies the velocity-dependent parameterizations of thermal and haline transfer coefficients from Holland and Jenkins [1999]:

$$
\begin{gathered}
\gamma_{T, S}=\frac{u_{*}}{\Gamma_{\text {turb }}+\Gamma_{\text {mole }}^{T, S}} \\
\Gamma_{\text {turb }}=\frac{1}{\kappa}\left(\frac{u_{*}^{2} \xi_{N} \eta_{*}^{2}}{|5 f v|}\right)+\frac{1}{\left(2 \xi_{N} \eta_{*}\right)}-\frac{1}{\kappa} \\
\Gamma_{\text {Mole }}^{T, S}=12.5(\mathrm{Pr}, \mathrm{Sc})^{2 / 3}-6 \\
u_{*}^{2}=c_{d}\left(u_{m}^{2}+v_{m}^{2}\right),
\end{gathered}
$$

where $\gamma_{T / S}$ is the thermal/haline exchange velocity, $\Gamma_{\text {turb }}$ is the turbulent transfer parameter, and $\Gamma_{\text {mole }}^{T, S}$ is the ther$\mathrm{mal} /$ haline molecular transfer parameter; $\kappa=0.4$ is von Kármán's constant, $\xi_{N}=0.052$ is a stability constant, $\eta_{*}=1$ is a stability parameter, $f$ is the Coriolis parameter, $v=1.95 \times 10^{-6} \mathrm{~m}^{2} \mathrm{~s}^{-1}$ is the kinematic viscosity of seawater, $\operatorname{Pr}=13.8$ is the molecular Prandtl number, and $\mathrm{Sc}=2432$ is the molecular Schmidt number; $c_{d}=1.5 \times 10^{-3}$ is the drag coefficient and $u_{m}$ and $v_{m}$ are the ocean surface layer velocity components (here we define the ocean surface layer to be the first $10 \mathrm{~m}$ of ocean immediately beneath the ice base). It can be seen from (3) that if conduction of heat through the ice shelf is ignored, the melt rate $(m)$ can be expressed as the 

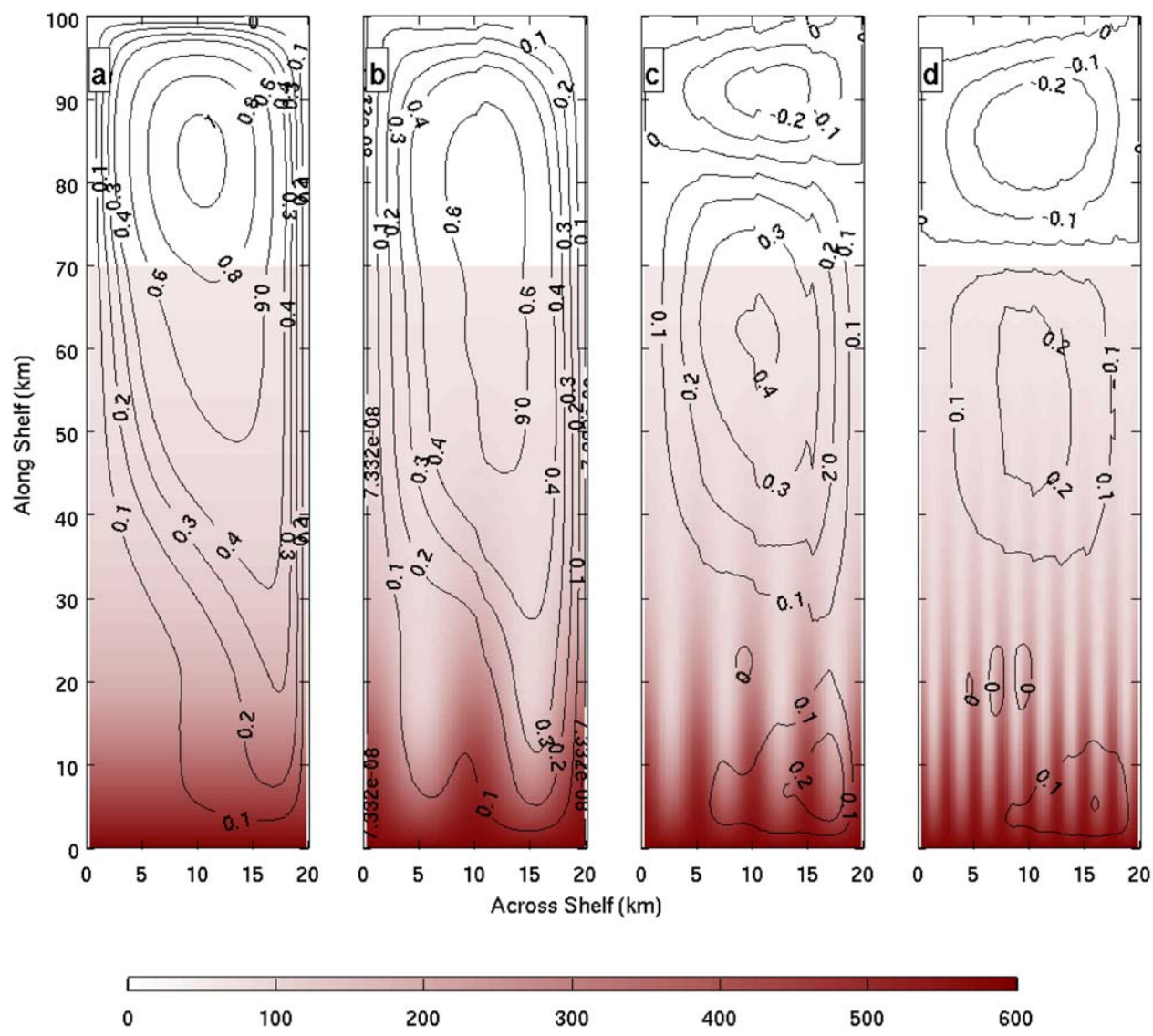

Figure 3. Barotropic streamfunction (contours) overlying ice draft (colored) for (a) 0-channel, (b) 2channel, (c) 4-channel and (d) 8-channel cases.

product of the friction velocity, $u_{*}$ and thermal driving $\left(T-T_{b}\right)$ [Holland et al., 2008b].

[14] A Cartesian grid with spacing of $250 \mathrm{~m}$ in the horizontal and $10 \mathrm{~m}$ in the vertical was chosen, and partial cells with a minimum height of $0.5 \mathrm{~m}$ were used to better represent the ice-shelf base. The calculation of ice-shelf basal melting is dependent on the ocean properties beneath the ice, for which we use the simple method of Losch [2008], which takes the mean temperature and salinity from all cells within a distance $d z$ from the ice base $(10 \mathrm{~m}$ in this configuration). This distance spans both the partial cell and a portion of the full cell below it. We also use the mean velocity components $\left(u_{m}\right.$ and $\left.v_{m}\right)$ over a distance of $d z$ to calculate the friction velocity $u_{*}$. The velocity in the center of a cell is calculated from $v$ velocity components at the north and south edges of the cell and $u$ velocity components on the east and west edges (MITgcm uses a "c" grid), so the calculation of the friction velocity $u_{*}$ is dependent on eight $u_{m}$ and $v_{m}$ velocity components in total.

[15] The model is hydrostatic with a free surface and was spun up with a $60 \mathrm{~s}$ time-step until steady after 5 years. Unless stated otherwise all results are presented as monthly averages. The model uses a horizontal diffusivity of $2.5 \mathrm{~m}^{2}$ $\mathrm{s}^{-1}$, a vertical diffusivity of $1.4 \times 10^{-4} \mathrm{~m}^{2} \mathrm{~s}-1$, a vertical eddy viscosity of $2 \times 10^{-3} \mathrm{~m}^{2} \mathrm{~s}^{-1}$, a horizontal eddy viscosity of $15 \mathrm{~m}^{2} \mathrm{~s}^{-1}$, and a horizontal biharmonic viscosity of $2.5 \mathrm{~m}^{4} \mathrm{~s}^{-1}$. A third-order flux-limited advection scheme is used. The domain is an $f$-plane with a Coriolis parameter of $1.4301 \times 10^{-4} \mathrm{~s}^{-1}$, equivalent to a latitude of $80^{\circ} \mathrm{N}$.

\section{Results}

\subsection{Flow within Cavity}

[16] Within the fjord there is a Coriolis-controlled circulation bringing warm modified Atlantic Water into the cavity along the western boundary of the domain (Figure 3). A return flow transports water out of the cavity along the eastern boundary. The warm water melts the ice base, introducing a source of freshwater and hence buoyancy. This buoyant meltwater forms a cooler plume rising against the base of the ice shelf (Figure 4), introducing an overturning element to the cavity circulation. While this water is warmer than the localized freezing point it will continue to melt the ice base.

[17] The barotropic stream function beneath an ice shelf with no basal channels (Figure 3a) shows a strong cyclonic circulation within the domain, with a fast flow against the eastern wall (Coriolis-favored), as found previously [e.g., Losch, 2008]. The flow returning under the ice shelf on the western boundary brings warm fjord water toward the ice shelf and diverts across the ice shelf to feed this jet, approximately $40 \mathrm{~km}$ north of the grounding line. As channels are introduced to the base of the ice shelf (Figures 3b-3d) a number of changes occur. The asymmetric nature of the stream function and the strength of the barotropic circulation 


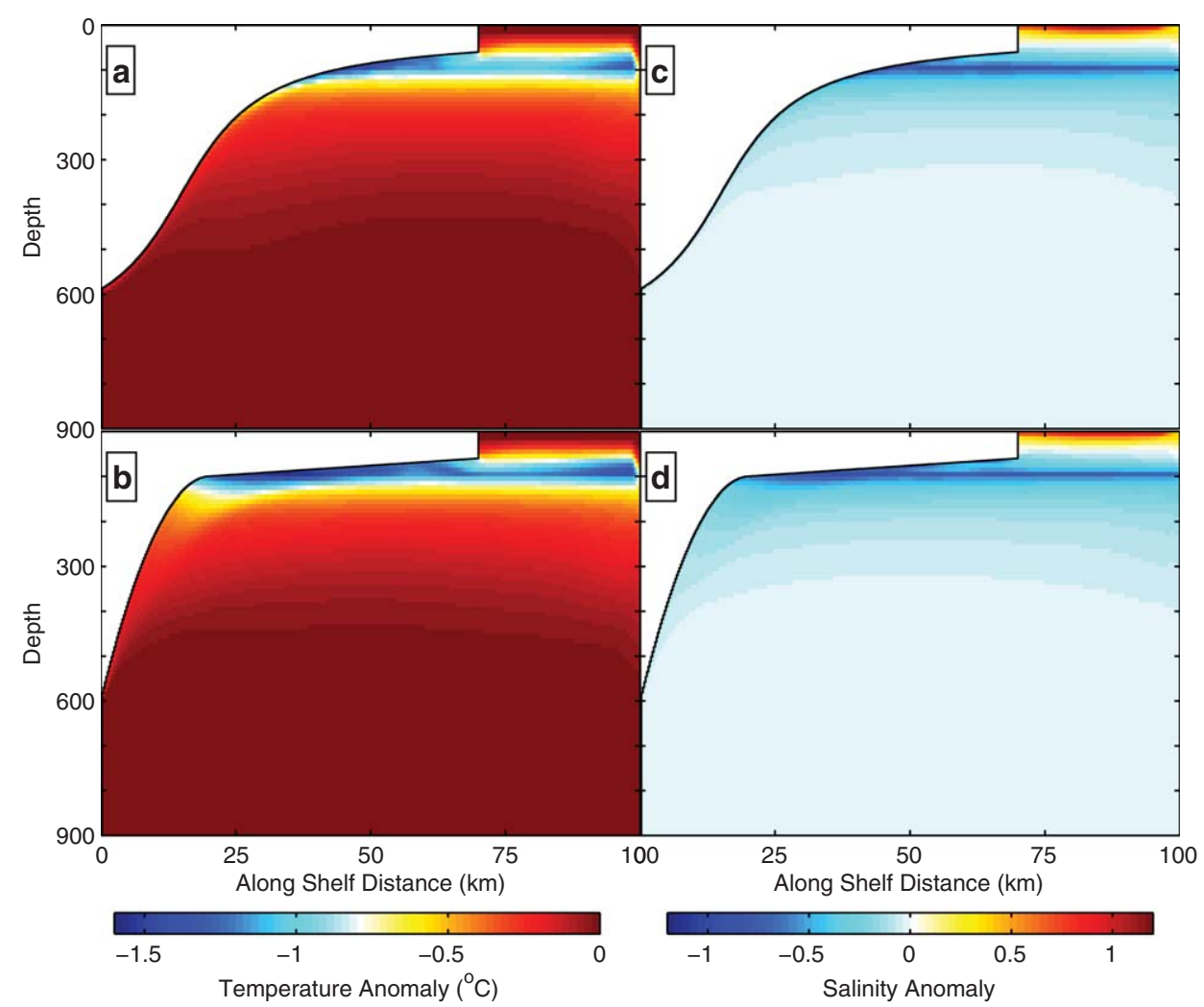

Figure 4. Anomaly profiles for the 2-channel case showing (a) temperature anomaly along the keel down the center of the domain, (b) temperature anomaly along the crest of the eastern channel, (c) salinity anomaly along the keel down the center of the domain, and (d) salinity anomaly along the crest of the eastern channel.

decreases as the number of channels increases. This weakening occurs in conjunction with a decrease in ice-shelf basal melting (see below), which reduces the buoyancy forcing on the circulation. This reduces the supply of heat to the cavity and ice base, in turn reducing the level of basal melting and hence further reducing the buoyancy forcing. Figures $3 \mathrm{c}$ and $3 \mathrm{~d}$ show that when there are more than four basal channels, a separate anticyclonic circulation is spun up in the open ocean section at the mouth of the fjord.

[18] The restoring on the northern boundary generates a northward dip in the isopycnals that would set up an anticyclonic circulation. However, for a small number of channels, the higher level of melting leads to a strong flow exiting the cavity on the eastern boundary, which is stronger than the effect of restoring, resulting in one cyclonic circulation spanning the whole domain. As the number of channels increases, the mean melt rate reduces (see below), which reduces the strength of the flow exiting the cavity, until the effect of restoring becomes stronger. This sets up an anticyclonic circulation near the northern boundary, which grows and becomes stronger as the exiting flow becomes weaker with the addition of further channels.

[19] The effect of the northern boundary was examined by extending the open ocean section of the domain by a further $70 \mathrm{~km}$. This resulted in a greater separation between the freshening at the ice front due to the exiting of meltwater from the cavity and the restoring at the northern boundary.
This greater separation led to a shallowing of the isopycnals and in turn a reduction in flow speed. The slower flow in the extended domain led to weaker ice-shelf melting; however, the sensitivity of the melt to the number of channels as described in the following sections was unaltered.

[20] The path of the buoyant meltwater plume formed when the warm modified Atlantic Water interacts with the ice is apparent from the north-south sections of temperature and salinity anomalies (Figure 4). This figure shows the difference between the temperature and salinity profiles at the end of the model run and their corresponding initial conditions, for the 2-channel case. The meltwater is cooler and fresher than the initial deep water and flows up within the channels until it reaches neutral buoyancy at the prescribed pycnocline, detaches from the ice-shelf base, and flows northward away from the ice shelf. This occurs approximately $20 \mathrm{~km}$ north of the grounding line and bears a striking resemblance to the observational interpretations of Johnson et al. [2011]. This flow is contained within the channels until the keels become shallower than the pycnocline depth approximately $40 \mathrm{~km}$ north of the grounding line. The section of the ice shelf shallower than the pycnocline underwent little or no melting irrespective of the number of channels.

\subsection{Basal Melting}

[21] When there are no channels in the base of the ice shelf, a strong geostrophically balanced boundary current is formed in the ocean surface layer, rising along the eastern 

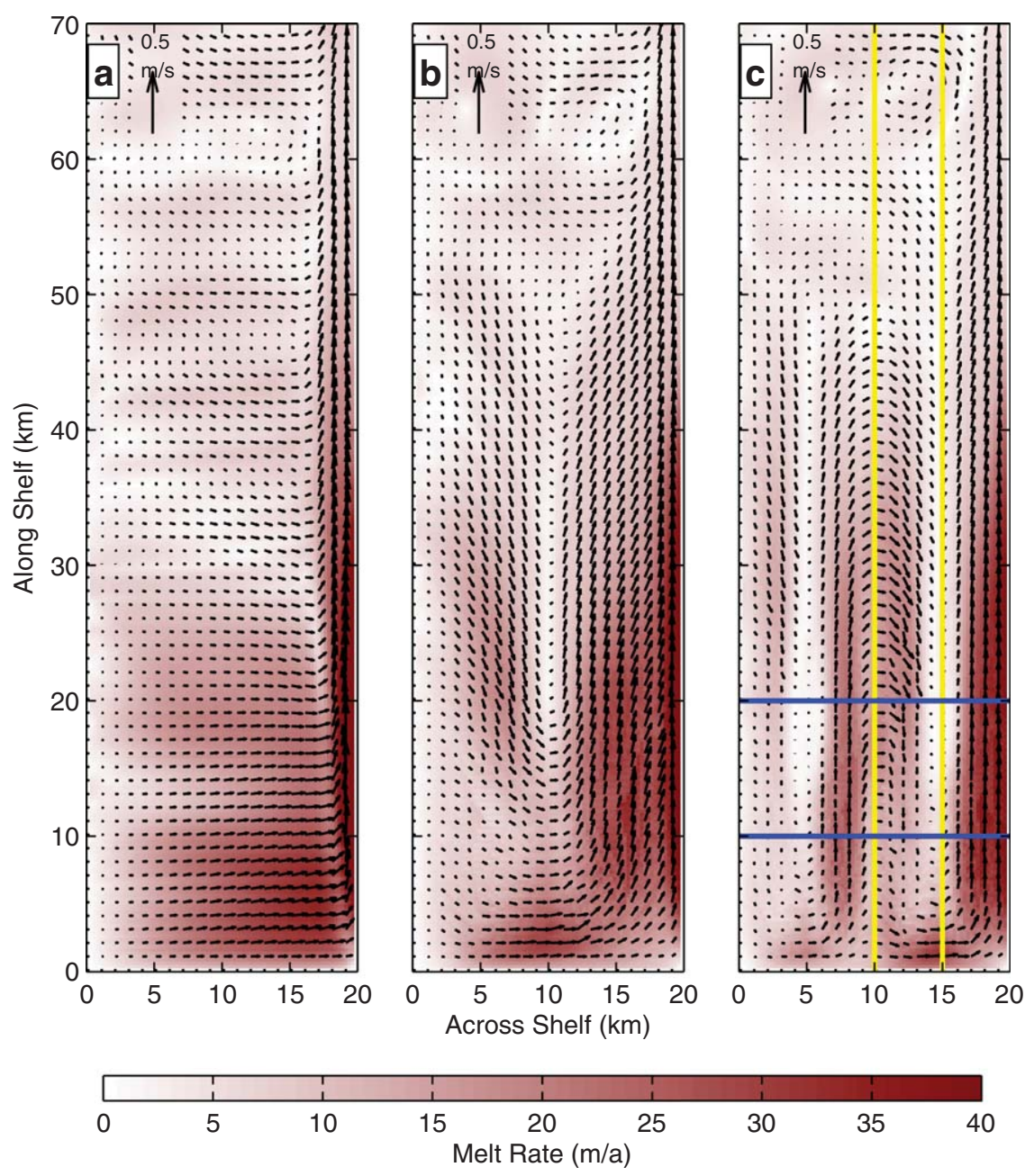

Figure 5. Modeled ocean surface layer velocities for (a) 0-, (b) 1-, and (c) 2-channel cases overlain on basal melt rates (m/a). Vectors are shown every four grid points. The yellow lines in Figure 5c indicates the location of the profiles shown in Figure 4, while the blue lines show the location of the profiles shown in Figure 11.

boundary, and leaning on the right-hand wall of the fjord (Figure 5a) [e.g., Holland et al., 2008b]. Due to the velocity dependence of melting, the strongest basal melting is focussed underneath the strongest part of the boundary current. The Rossby deformation radius $\left(L_{R}\right)$ of the buoyant meltwater layer in the no-channel case can be found from:

$$
L_{R}=\frac{\left(g^{\prime} D_{m}\right)^{1 / 2}}{|f|},
$$

where $g^{\prime}=g \frac{\Delta \rho}{\rho_{0}}$ and $D_{m}$ are the reduced gravity and depth of the meltwater layer, respectively. A field of radii was calculated using $\rho_{0}=1028 \mathrm{~kg} \mathrm{~m}^{-3}, D_{m}=40 \mathrm{~m}$, and $\Delta \rho$ equal to the difference in ocean density over a distance $D_{m}$. The maximum deformation radius of this field is $2.7 \mathrm{~km}$, which is the length scale that rotational effects become important. We would expect the width of the geostrophically balanced boundary current to be in agreement with this, and we can see from Figure $5 \mathrm{a}$ that indeed the width is approximately $2.5-3 \mathrm{~km}$.
[22] The introduction of channels prevents the formation of this wall-bounded current, which is instead replaced by a circulation within each channel (Figures $5 \mathrm{~b}$ and $5 \mathrm{c}$ ). These circulations consist of a southward flow leaning on the left-hand slope of the channel and a northward flow on the right-hand slope. There is little flow in the channel crests. In the 2-channel case there is some transfer across the keel between the channels in an eastward direction, leading to slightly faster flow and stronger melting in the more easterly channel. Within each channel, melting is strongest in the steepest part of the ice shelf near the grounding line, and on the right-hand slope of the channels. The current is still strongest on the eastern boundary of the domain, but the maximum flow is decreased, as is the peak melting associated with it. The melt rate is low near the ice front where the mixed layer is detached from the ice base and the flow is not topographically constrained.

[23] The mean melt rate for the whole ice shelf is roughly the same for the 0 - and 1-channel cases, but as more channels are introduced, the mean melt rate decreases 

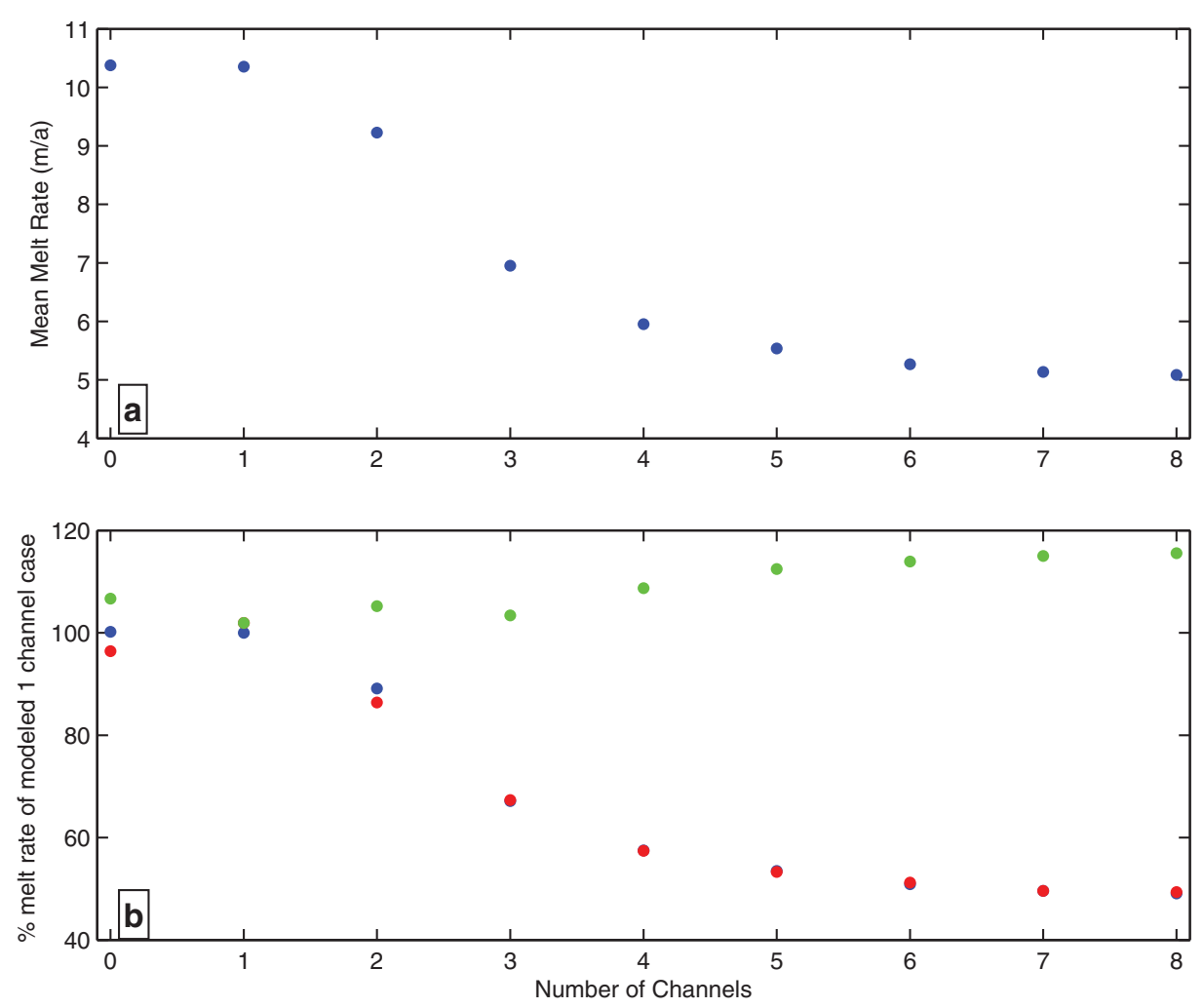

Figure 6. (a) Mean melt rate as a function of number of basal channels. (b) Predicted melt rate as proportion of 1-channel model case for modeled results (blue), keeping $\left(T-T_{\mathrm{b}}\right)$ constant (red), and keeping $u *$ constant (green).

(Figure 6a). There is a reduction of approximately $40 \%$ in melting between the 1- and 4-channel cases, after which the sensitivity of the mean melt rate to the number of channels declines, with only a further $8 \%$ reduction between the 4- and 8-channel cases.

[24] To a good level of approximation, the melt rate is proportional to the product of frictional velocity and thermal driving (neglecting heat conduction in (3)) [Holland and Jenkins, 1999; Holland et al., 2008b]. To investigate the relative effects of each of these quantities, we first calculate the spatial-mean values of both for each model run. We then investigate their effect by substituting these values into $(3-8)$ and calculating the domain-average melt rate. We investigate the effect of $u_{*}$ in the cases with different channels by keeping $\left(T-T_{b}\right)$ constant at the one-channel modeled mean, and likewise we investigate $\left(T-T_{b}\right)$ by keeping $u *$ constant at the 1-channel modeled mean.

[25] Figure $6 \mathrm{~b}$ shows modeled and derived melt rates as a percentage of the modeled 1-channel case. The blue dots represent the modeled mean melt rates as a percentage of the 1-channel modeled mean melt rate. The green dots represent the derived mean melt rates when varying only the mean $\left(T-T_{b}\right)$ and the red dots represent derived mean melt rates when varying only the mean $u_{*}$. The melt rate estimates when varying $\left(T-T_{b}\right)$ are basically constant as the number of channels increases, in contrast to the modeled melt rates. Varying $u *$ provides melt rate estimates which are consistent with the modeled melt rates, implying that a change in friction velocity drives the change in melting as more channels are introduced. An understanding of the mechanism behind the change in $u_{*}$ is, therefore, necessary to understand the change in the mean melt rates.

\subsubsection{Wide Channels}

[26] To understand the initial strong decrease in $u_{*}$, and hence mean basal melt rates, we consider the difference in ocean surface layer $u_{*},\left|u_{m}\right|$ and $\left|v_{m}\right|$ between the 1- and 2-channel cases (Figure 7). All three differences show a decrease as the number of channels is increased. Comparison of the spatial patterns show that there is a higher spatial correlation between the differences in $u_{*}$ and $\left|v_{m}\right|(0.847)$ than the differences in $u_{*}$ and $\left|u_{m}\right|$ (0.394), when comparing the first $50 \mathrm{~km}$ of the ice shelf, meaning that the majority of the decrease in $u_{*}$ can be explained by a decrease in $\left|v_{m}\right|$. The final $20 \mathrm{~km}$ of the ice shelf was excluded from the analysis as the channel depth is less than $10 \mathrm{~m}$ under this section of ice shelf, and the ocean surface layer is no longer topographically constrained. Therefore, it is necessary to understand the decrease in $\left|v_{m}\right|$.

[27] Figure 8 shows across-shelf profiles of $\left|v_{m}\right| 20 \mathrm{~km}$ downstream of the grounding line for the 1- and 2-channel cases. It can be seen that the maximum velocity is similar in both cases (excluding the current leaning on the eastern boundary wall). The main difference between the cases is 

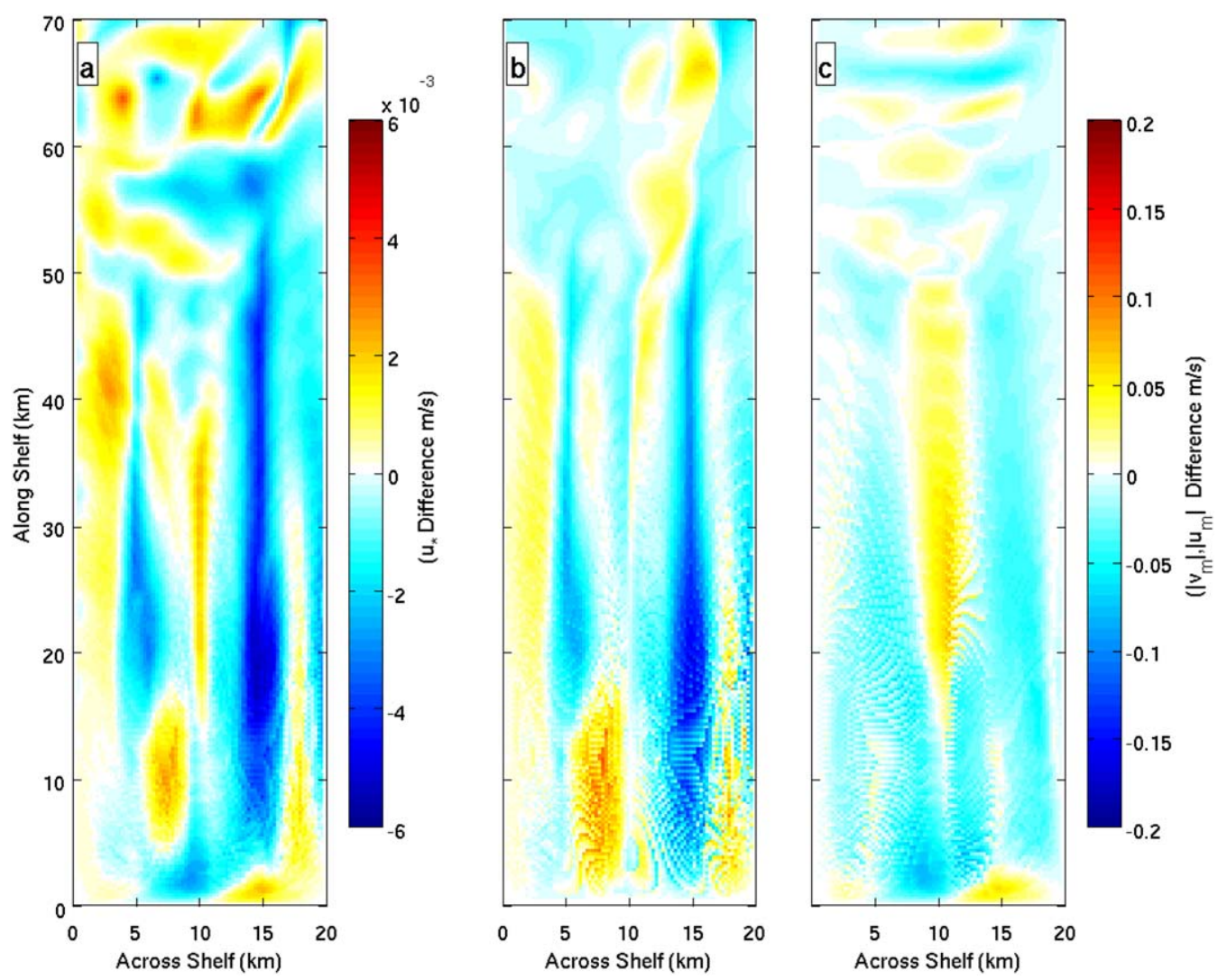

Figure 7. Difference in monthly averaged (a) $u_{*}$, (b) $|v|$, and (c) $|u|$ between 2- and 1-channel cases. All panels show the 1-channel field subtracted from the 2-channel field.

the inclusion of more "no flow" regions; the 1-channel case has one crest, whilst the 2-channel case has two crests and one keel. These extra stagnant regions lead to a decrease in mean $\left|v_{m}\right|$ and hence $\boldsymbol{u}_{*}$.

[28] Figures 9 and 10 show the individual terms in the momentum balance for the 1- and 2-channel cases in the ocean surface layer. Unlike all other variables these are plotted as an instantaneous "snapshot" to ensure they sum to zero. In both cases, the primary balance is between the pressure gradient and Coriolis terms, so the flow is basically geostrophic. This means that the magnitude of the $v$ velocity component is governed by the across-shelf pressure gradients. As more channels are introduced to the ice shelf, the across-shelf gradients in ice draft increase. One might expect that the across-shelf isopycnal slope, and hence pressure gradients, is proportional to the ice base slope (as implicit in some simplified models) [e.g., Jenkins, 1991]. This would imply that the speed of the geostrophic north-south flow on the channel sides would increase as the number of channels is increased, compensating the addition of "no flow" areas as described above. However, this is not the case (Figure 8).

[29] Figure 11 shows across-shelf density gradients and isopycnals for the 1- and 2- channel cases. The largest density gradients are closest to the channel slopes, in the rising meltwater, whilst in the middle of the channels the isopycnals are flat. Density gradients are similar in the 1- and 2-channel cases. It is this consistency in isopycnal gradients, despite a doubling of ice-shelf draft gradients, that causes the constant maximum flow speed seen in Figure 8, and therefore the overall deceleration caused by the introduction of "no flow" regions.

[30] In summary, for 0-4 channels, increasing the number of channels increases the number of "no-flow" regions, beneath ice keels and crests. The isopycnal gradients beneath ice slopes do not increase to compensate this effect as the ice steepens, so the mean north-south velocity decreases overall. This local reduction in velocity in turn leads to a rapid local reduction in $u_{*}$ and hence the overall melt rate.

\subsubsection{Narrow Channels}

[31] Figure 6 shows that cases with a larger number of channels have a weaker melting sensitivity. Figure 12 shows the mixed-layer flow pattern and melt rate for such cases. As more basal channels are added, the ocean surface layer circulation within each channel changes from a two-way flow located on both channel slopes, to a single northward flow in the center of the channel. This represents a change of flow from a geostrophic horizontal circulation to a vertical overturning circulation.

[32] This move toward an ageostrophic circulation can be seen by comparing the size of the sum of the ageostrophic momentum terms (advection, viscosity, drag) to 


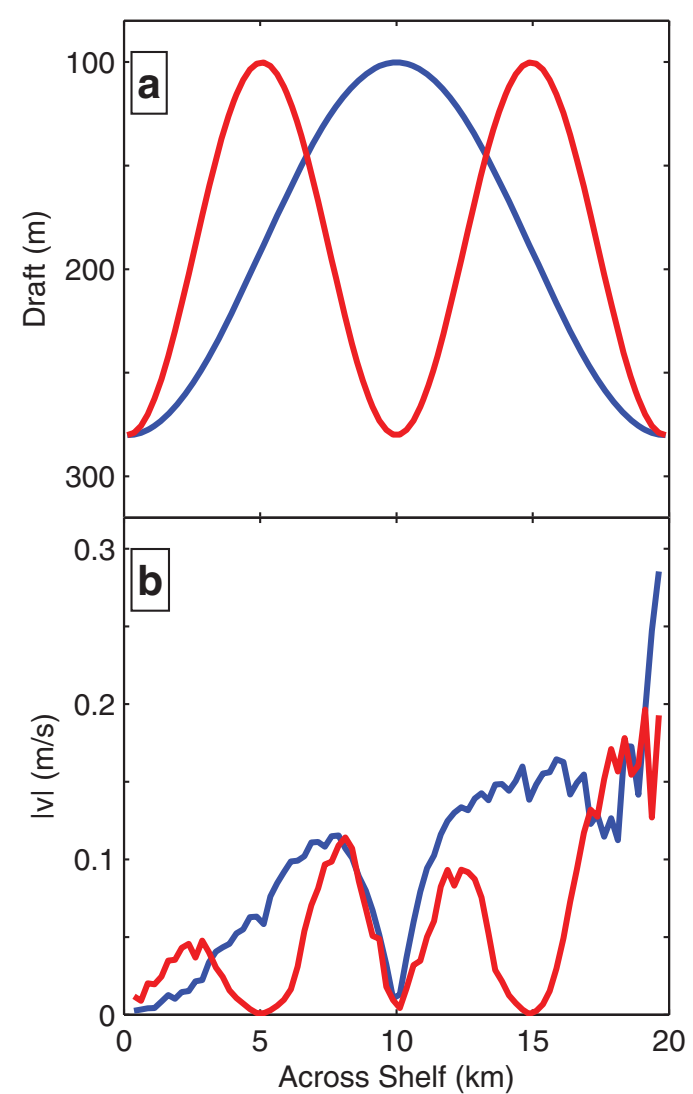

Figure 8. (a) Ice draft profiles and (b) $|v|$ velocities 20 $\mathrm{km}$ downstream of the grounding line (1 channel - blue, 2 channels - red).

the size of the pressure momentum term. This value $R$ is calculated by

$$
R=\overline{\left|\frac{M_{p}+M_{c}}{M_{p}}\right|}
$$

where $M_{p}$ is the pressure momentum term and $M_{c}$ is the Coriolis momentum term. The sum of the momentum terms is zero, so if the pressure and Coriolis terms are added together the residual must equal the sum of the other momentum terms. If the flow is purely geostrophic, then the pressure and Coriolis terms will cancel and $R$ would have a value of zero. As the flow becomes more ageostrophic, the other terms become larger and the value of $R$ would increase with no upper bound.

[33] As the geostrophic $v$-velocity component is determined by the $u$-momentum balance, we consider the ratio of these terms only. As the number of channels increase from 1 to 8 , the value of $R$ for the $u$-momentum terms increases from 0.381 to 1.253 . This shows that the circulation is becoming more ageostrophic with the addition of more channels.

[34] As the circulation is ageostrophic, the flow speed is no longer governed by across-shelf density gradients, and all of the above arguments break down. The overturning circulation is instead driven by mean gradients in the along-shelf direction, which are unaffected, on average, by the number of channels. Thus, the melt rate is less affected by the number of channels.

[35] Insight into this change of flow regime can be illustrated by the investigation of the buoyant meltwater layer deformation radius (10). The mean deformation radius was found to be approximately $2 \mathrm{~km}$ for all of the model runs. This deformation radius suggests that, for channels narrower than $4 \mathrm{~km}$, a geostrophic circulation would not form. This channel width coincides with the 5-channel case, which is the number of channels at which the circulation changes from geostrophic to overturning (Figure 12) and the sensitivity of melting to channel number changes (Figure 6).

[36] Further insight into this change in circulation can be illustrated by varying the horizontal and vertical viscosity values. Figure 13 shows the mean melt rates of simulations with 1-8 channels for the original prescribed viscosity values along with halved and doubled viscosities. As the viscosity is increased, the sensitivity of the melt rate to the number of channels ceases when there are fewer basal channels, and when the viscosity is decreased, the melt rate is sensitive to channel number for all cases tested.

[37] Under a reversing geostrophic circulation regime, there is a high level of horizontal shear in the center of the channels, which viscosity acts to smooth out. The viscosity effect described shows that for a given channel width, there is a viscosity which does not permit this horizontal shear, changing the flow from reversing to overturning. Altering the viscosity changes the point at which the circulation changes from reversing to overturning. For our chosen default values, the results are only slightly affected by lower viscosity, so we conclude that the switch from a geostrophic to an ageostrophic momentum balance is the dominant cause of the switch to an overturning circulation.

[38] Diffusivity effects were investigated by halving and doubling the prescribed heat and salt diffusivities. Decreasing the diffusivities resulted in a steepening of the isopycnal gradients (Figure 14a), leading to an increase in ocean surface layer flow speed and mean melt rates. Increasing the diffusivities resulted in a shallowing of the isopycnal gradients (Figure 14c), leading to a decrease in ocean surface layer flow speed and mean melt rates. Altering the diffusivities did not lead to a change in the point at which the mean basal melt rates start to plateau.

\section{Conclusion}

[39] We have used the MITgcm to assess the impact of ice-shelf basal channels on ice melting and circulation within an ice-shelf cavity. We find that the inclusion of channels alters the flow of the ocean surface layer beneath the ice shelf, changing the focus and intensity of the melt. In agreement with the findings of Gladish et al. [2012], the overall mean melt rate decreases as the number of channels increases. Further, we find that for a small number of larger channels, this sensitivity is high, but for a greater number of smaller channels the sensitivity drops.

[40] We find that for larger channels, a geostrophic flow circulates around the channels. As channels are narrowed, more "no flow" regions are added beneath crests and keels, 


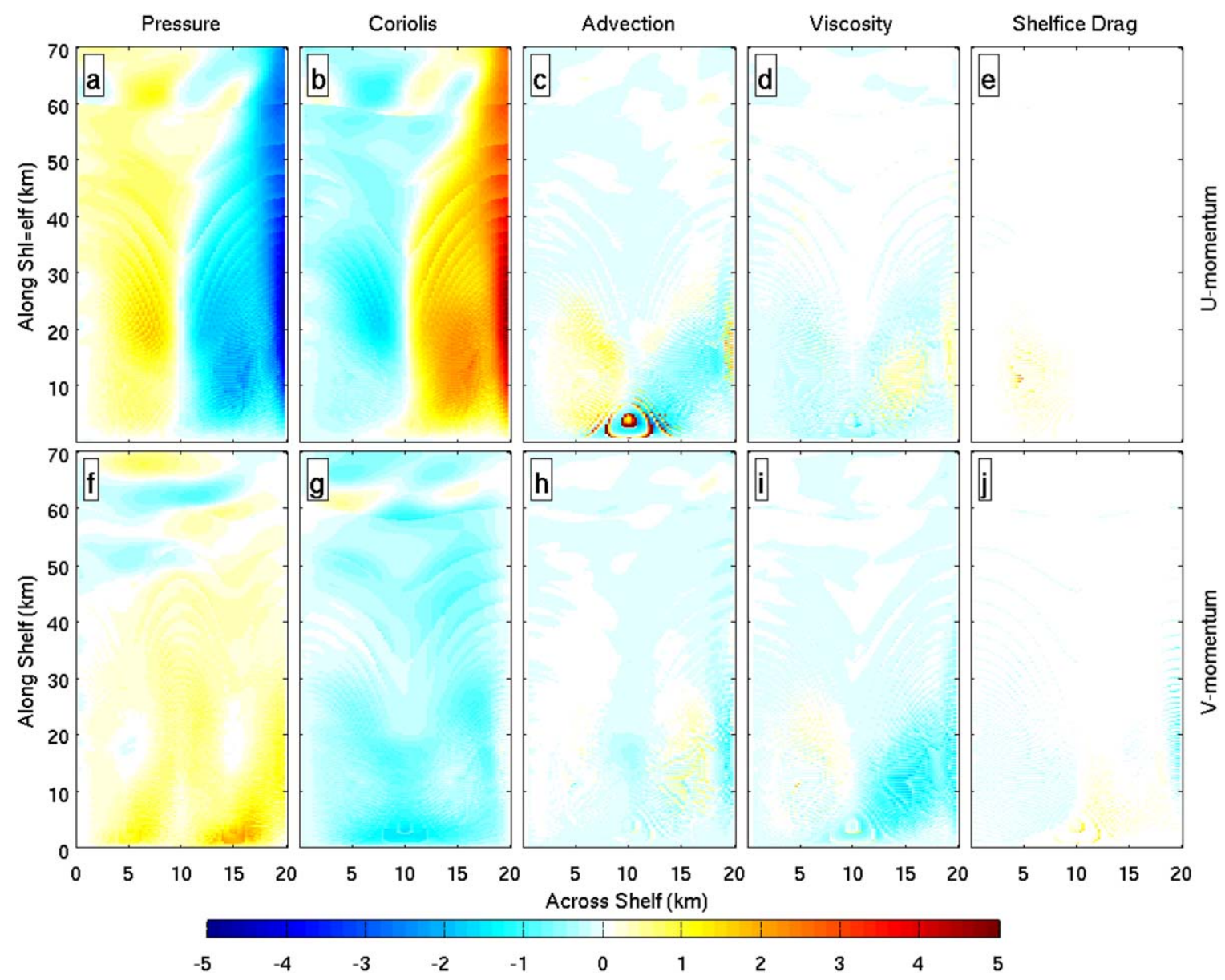

Figure 9. Instantaneous momentum terms for 1 -channel case. Top row is $u$-momentum; bottom row is $v$-momentum.

whilst geostrophic flow on slopes remains the same. This leads to a decrease in mean ocean surface layer flow, and therefore basal melting.

[41] For narrower channels however, this horizontally sheared circulation is not viable and is replaced by a slower, ageostrophic overturning circulation that is much less sensitive to the channel width. Varying the prescribed viscosity changes the number of channels permitted before the circulation changes from a geostrophic circulation to an overturning circulation, but at our chosen viscosity this transition is governed by the deformation radius.

[42] Dutrieux et al. [2013] suggested that melt-enhanced channel features near the grounding line rapidly reach maximum surface expression before thinning toward the ice front. Due to the static nature of the ice shelf we are not able to model this directly, however our modeled results suggest that strong melting in the steeper section of the channel, near the grounding line, would promote rapid channel growth, whilst melting further downstream on the channel keels would promote a widening and thinning of the channels, in agreement with Dutrieux et al. [2013] and the channel profiles seen in the ASTER DEM image (Figure 1).
[43] The presence of basal channels decreases the mechanical stability of an ice shelf [Rignot and Steffen, 2008; Vaughan et al., 2012]. However, the addition of channels also decreases an ice-shelf's susceptibility to basal melting for two reasons. First, the melting is more evenly distributed, moving away from predominantly beneath the Coriolis-generated boundary current to over more of the ice shelf. Second, the mean melt rate decreases. This stabilizing effect is a possible explanation as to why basal channels are observed in warm-water ice shelves in Greenland and Antarctica. If the channels stabilize ice shelves, ice shelves with channels are more likely to persist, and a "survivor bias" then makes them more likely to be observed.

[44] There are of course limitations to the model used in this study. Coupled models with an evolving ice shelf are required to test the full impact of the physical processes described here. The bathymetry beneath Petermann Glacier is unknown, however observational data show that there is a shallow sill separating a deep basin within Petermann Fjord from Hall Basin [Johnson et al., 2011]. The profile of the channels is also highly idealized, so we plan to model a realistic Petermann Ice Shelf domain with a more realistic 


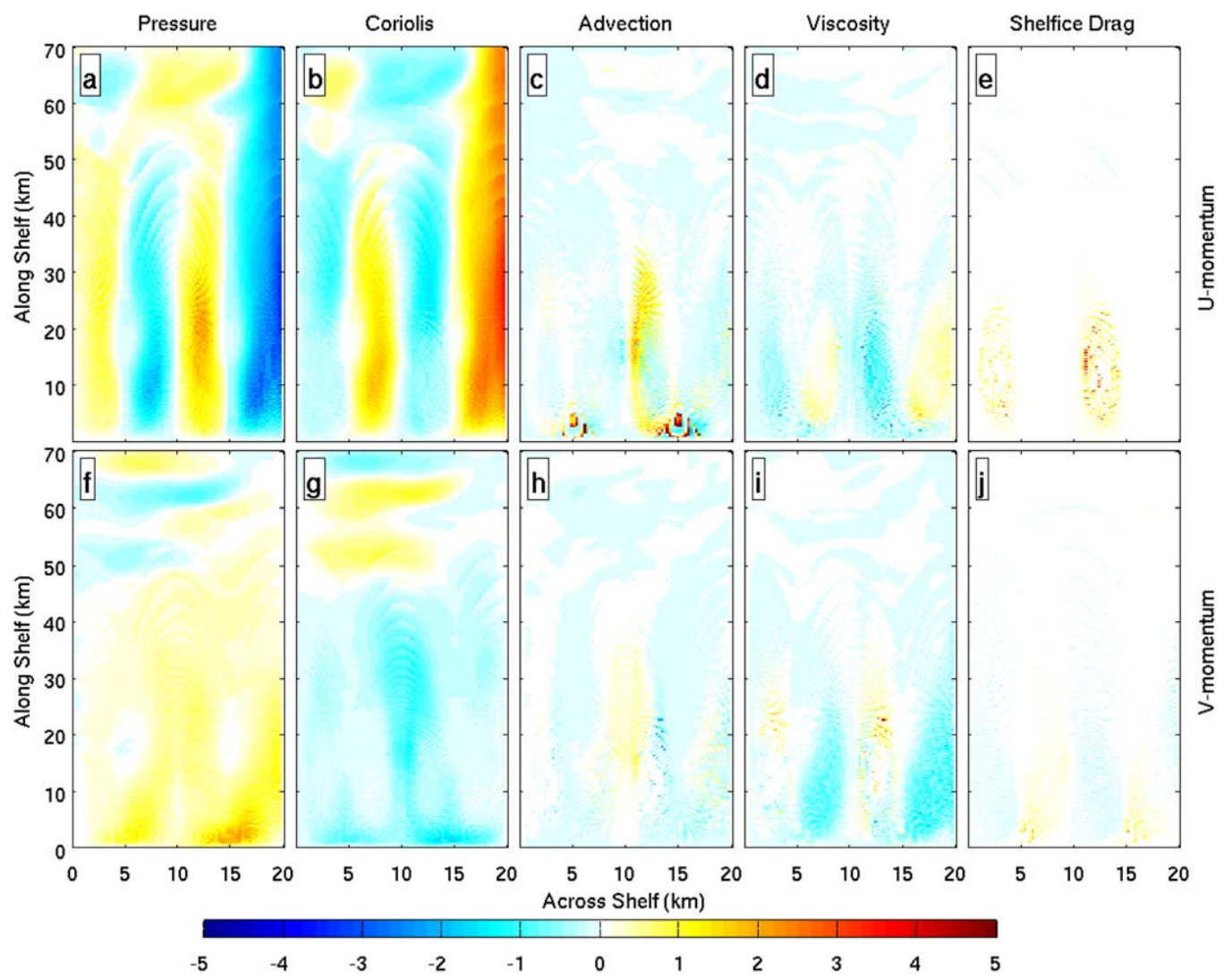

Figure 10. Instantaneous momentum terms for 2-channel case. Top row is $u$-momentum; bottom row is $v$-momentum.

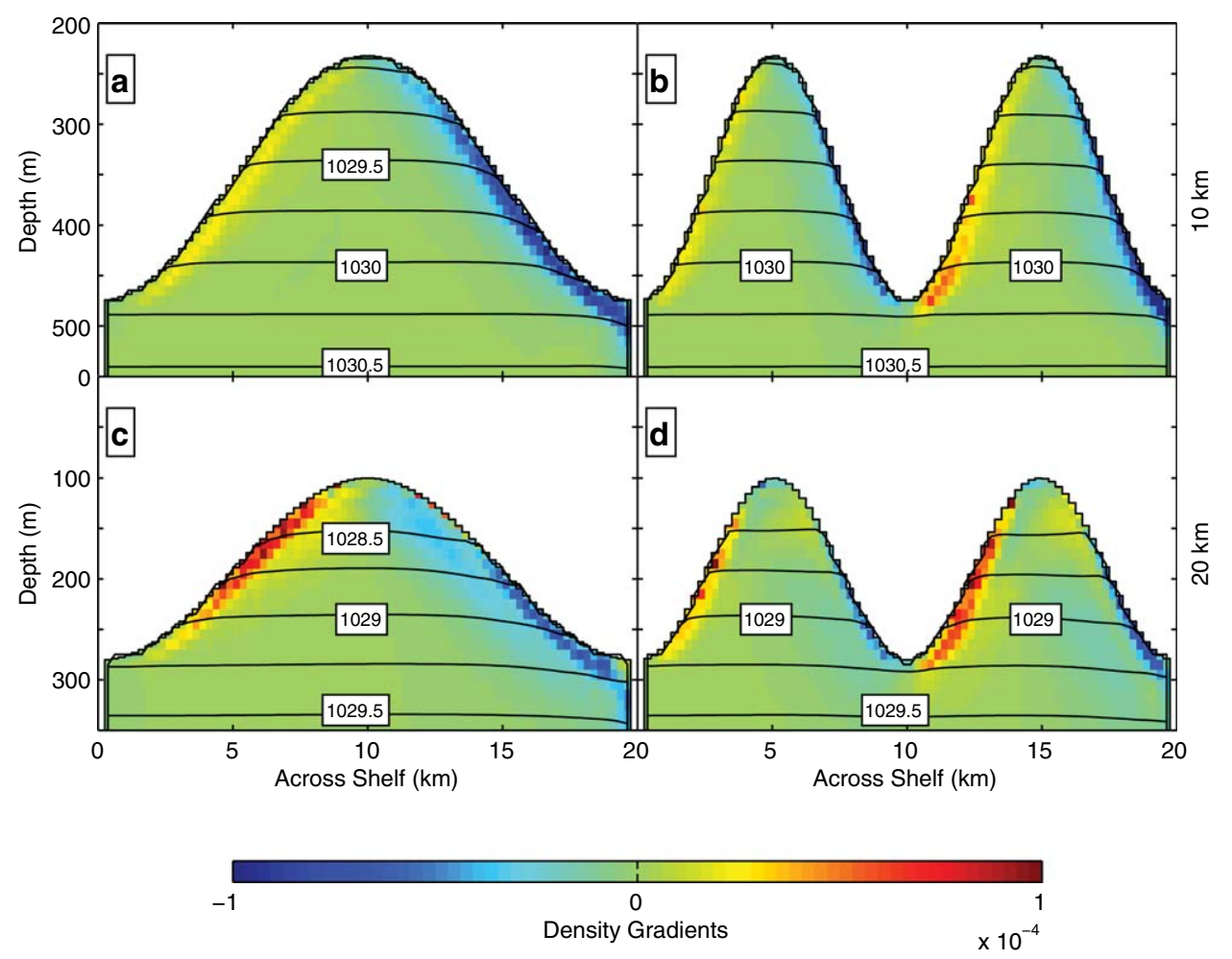

Figure 11. Density contours overlaying density gradients for 1- and 2-channel cases, $10 \mathrm{~km}$ and $20 \mathrm{~km}$ downstream from the grounding line. 

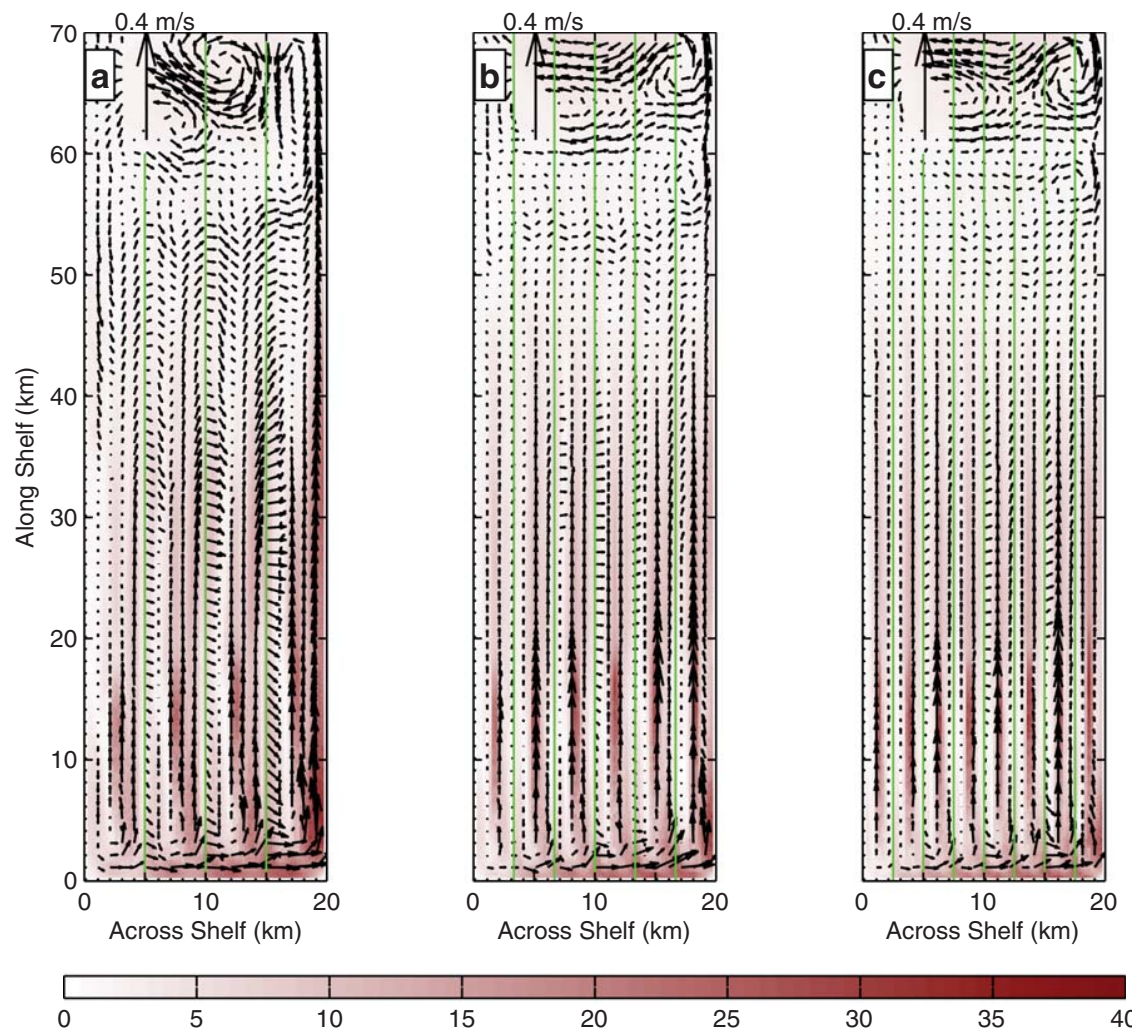

Figure 12. Modeled ocean surface layer velocities for (a) 4-, (b) 6-, and (c) 8-channel cases overlain on basal melt rates $(\mathrm{m} / \mathrm{a})$. Vectors are shown every 4 grid points. Green lines denote location of channel keels.

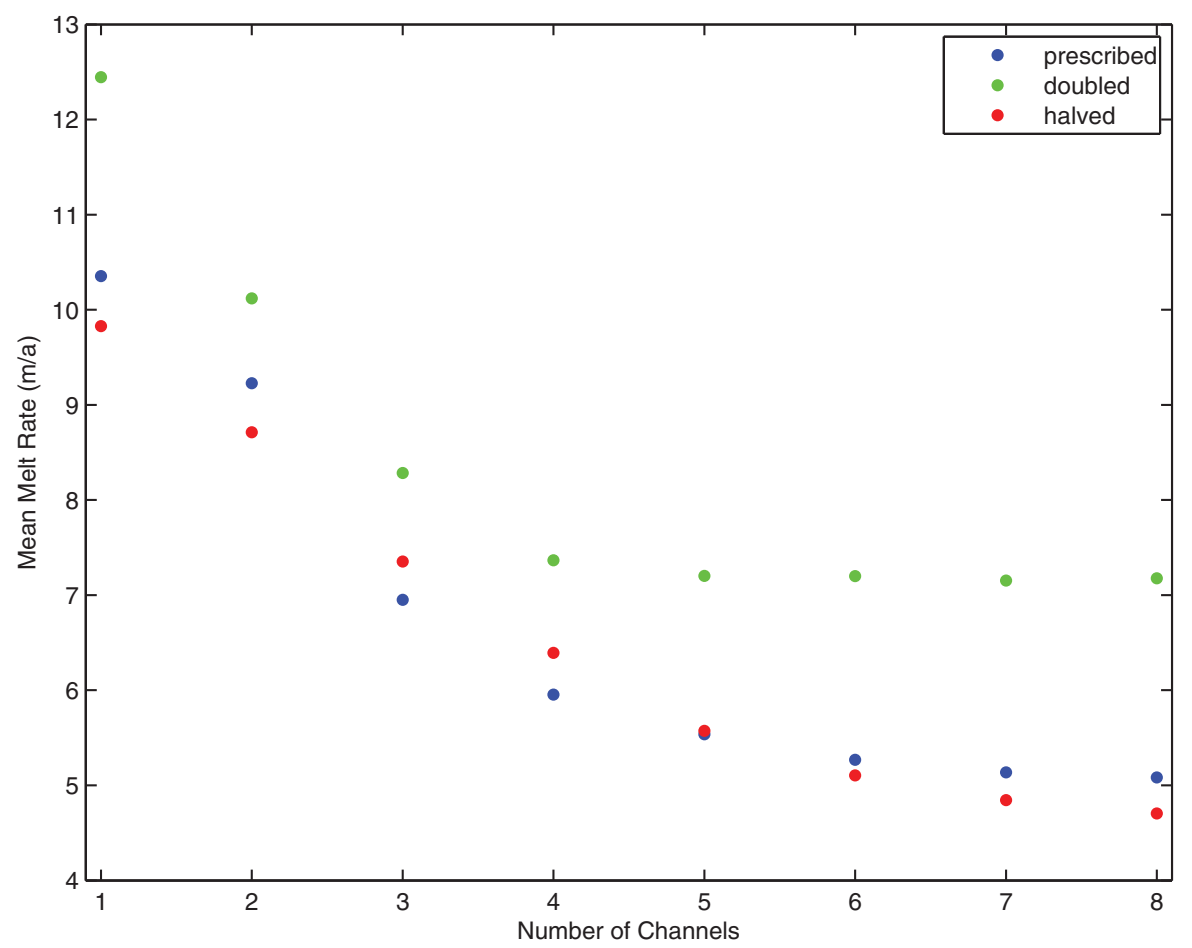

Figure 13. Modeled mean basal melt rates for 1 to 8 channels with standard viscosity (blue), halved viscosity (red) and doubled viscosity (green). 


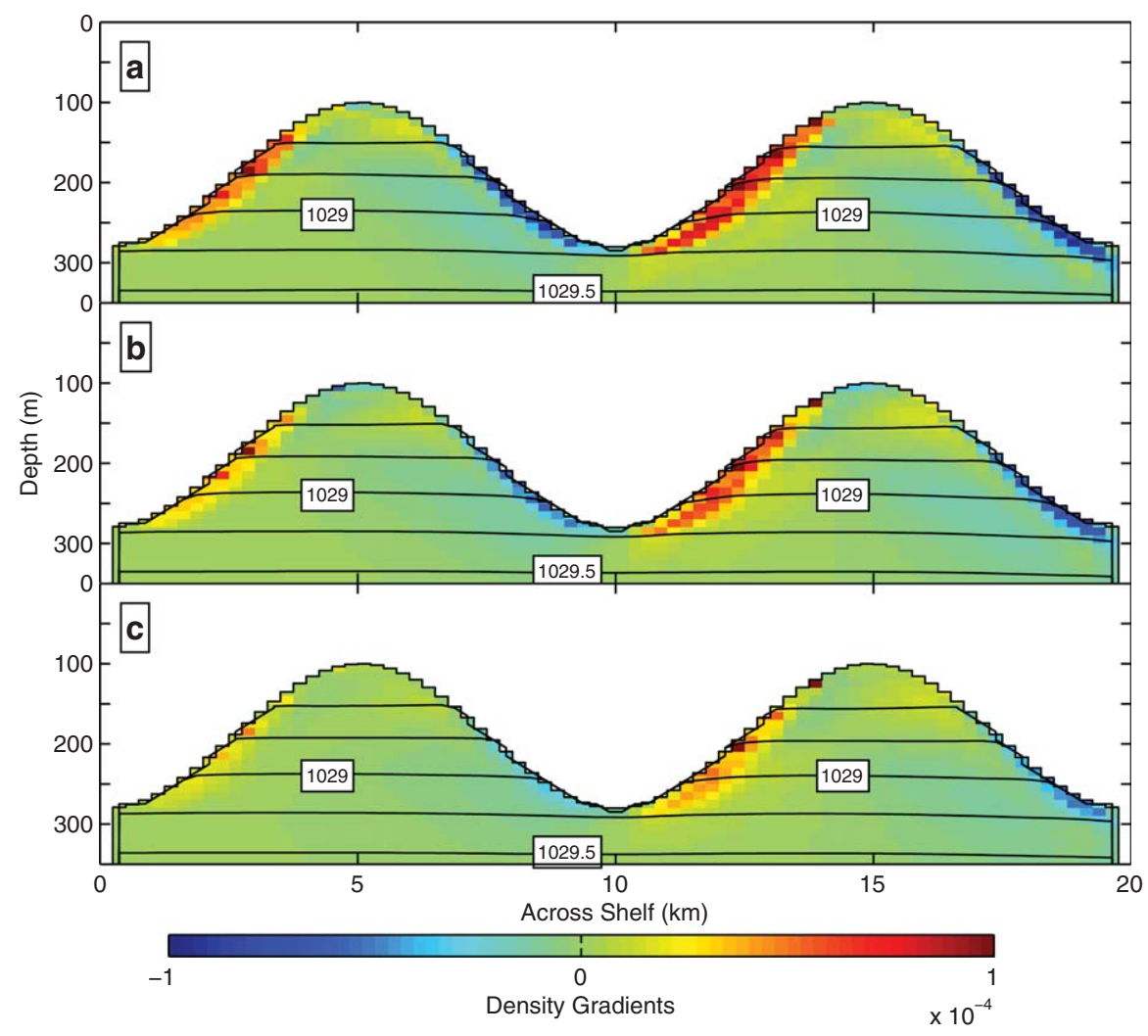

Figure 14. Density contours overlaying density gradients for the 2-channel case with (a) halved diffusivities, (b) standard diffusivities, and (c) doubled diffusivities.

bathymetry. A higher resolution model would allow us to model current subgrid scale processes and reduce the level of parameterization. The model is also limited by the lack of seasonal forcings, tides, and winds which will be included in further model studies.

[45] Acknowledgment. The work was supported by the UK Natural Environment Research Council under grant NE/I52797X/1.

\section{References}

Christoffersen, P., R. I. Mugford, K. J. Heywood, I. Joughin, J. A Dowdeswell, J. P. M. Syvitski, A. Luckman, and T. J. Benham (2011), Warming of waters in an East Greenland fjord prior to glacier retreat: Mechanisms and connection to large-scale atmospheric conditions, Cryosphere, 5(3), 701-714, doi:10.5194/tc-5-701-2011.

Dutrieux, P., D. G. Vaughan, H. F. J. Corr, A. Jenkins, P. R. Holland, I. Joughin, and A. Fleming (2013), Pine Island Glacier ice shelf melt distributed at kilometre scales, Cryosphere, 7, 1543-1555, doi:10.5194/tc7-1543-2013.

Falkner, K., et al. (2011), Context for the recent massive Petermann Glacier calving event, Eos Trans. AGU, 92(14), 117

Gladish, C., D. Holland, P. Holland, and S. Price (2012), Ice-shelf basa channels in a coupled ice/ocean model, J. Glaciol., 58(212), 1227-1244, doi: $10.3189 / 2012$ JoG12J003.

Hellmer, H. H., and D. J. Olbers (1989), A two-dimensional model for the thermohaline circulation under an ice shelf, Antarct. Sci., 1(04), 325-336.

Higgins, A. (1991), North Greenland glacier velocities and calf ice production, Polarforschung, 60(1), 1-23.

Holland, D., and A. Jenkins (1999), Modeling thermodynamic ice-ocean interactions at the base of an ice shelf, J. Phys. Oceanogr., 29(8), 1787-1800.
Holland, D. M., R. H. Thomas, B. De Young, M. H. Ribergaard, and B. Lyberth (2008a), Acceleration of Jakobshavn Isbrætriggered by warm subsurface ocean waters, Nat. Geosci., 1(10), 659-664, doi:10.1038/ngeo316.

Holland, P. R., A. Jenkins, and D. M. Holland (2008b), The response of ice shelf basal melting to variations in ocean temperature, J. Clim., 21(11), 2558-2572, doi:10.1175/2007JCLI1909.1.

Jenkins, A. (1991), A one-dimensional model of ice shelf-ocean interaction, J. Geophys. Res., 96, 20,671-20,677, doi:10.1029/91JC01842.

Johnson, H. L., A. Münchow, K. K. Falkner, and H. Melling (2011), Ocean circulation and properties in Petermann Fjord, Greenland, J. Geophys. Res., 116, C01003, doi:10.1029/2010JC006519.

Le Brocq, A. M., et al. (2013), Evidence from ice shelves for channelized meltwater flow beneath the Antarctic Ice Sheet, Nat. Geosci., 6(11), 945-948, doi:10.1038/ngeo1977.

Losch, M. (2008), Modeling ice shelf cavities in a z coordinate ocean general circulation model, J. Geophys. Res., 113, C08043, doi:10.1029/ 2007JC004368.

Mankoff, K., S. Jacobs, S. Tulaczyk, and S. Stammerjohn (2012), The role of Pine Island Glacier ice shelf basal channels in deep-water upwelling, polynyas and ocean circulation in Pine Island Bay, Antarctica, Ann. Glaciol., 53(60), 123-128, doi:10.3189/2012AoG60A062.

Marshall, J., A. Adcroft, C. Hill, L. Perelman, and C. Heisey (1997a), A finite-volume, incompressible Navier Stokes model for studies of the ocean on parallel computers, J. Geophys. Res., 102, 5753-5766, doi: 10.1029/96JC02775.

Marshall, J., C. Hill, L. Perelman, and A. Adcroft (1997b), Hydrostatic, quasi-hydrostatic, and nonhydrostatic ocean modeling, J. Geophys. Res., 102, 5733-5752, doi:10.1029/96JC02776.

Motyka, R. J., M. Truffer, M. Fahnestock, J. Mortensen, S. R. Rysgaard, and I. Howat (2011), Submarine melting of the 1985 Jakobshavn Isbræ floating tongue and the triggering of the current retreat, J. Geophys. Res., 116, F01007, doi:10.1029/2009JF001632.

Nick, F. M., A. Vieli, I. M. Howat, and I. Joughin (2009), Large-scale changes in Greenland outlet glacier dynamics triggered at the terminus, Nat. Geosci., 2(2), 110-114, doi:10.1038/NGEO394. 
Payne, A. J., P. R. Holland, A. P. Shepherd, I. C. Rutt, A. Jenkins, and I. Joughin (2007), Numerical modeling of ocean-ice interactions under Pine Island Bay's ice shelf, J. Geophys. Res., 112, C10019, doi:10.1029/ 2006JC003733.

Rignot, E., and K. Steffen (2008), Channelized bottom melting and stability of floating ice shelves, Geophys. Res. Lett., 35, L02503, doi:10.1029/ 2007 GL031765.

Sergienko, O. V. (2013), Basal channels on ice shelves, J. Geophys. Res. Earth Surf., 118, 1342-1355, doi:10.1002/jgrf.20105.

Shepherd, A., D. Wingham, and E. Rignot (2004), Warm ocean is eroding West Antarctic Ice Sheet, Geophys. Res. Lett., 31, L23402, doi:10.1029/ 2004 GL021106.
Shepherd, A., et al. (2012), A reconciled estimate of ice-sheet mass balance, Science, 338(6111), 1183-1189, doi:10.1126/science. 1228102 .

Straneo, F., D. A. Sutherland, D. Holland, C. Gladish, G. S. Hamilton, H. L. Johnson, E. Rignot, Y. Xu, and M. Koppes (2012), Characteristics of ocean waters reaching Greenland's glaciers, Ann. Glaciol., 53(60), 202210, doi:10.3189/2012AoG60A059.

Vaughan, D. G., H. F. J. Corr, R. A. Bindschadler, P. Dutrieux, G. H Gudmundsson, A. Jenkins, T. Newman, P. Vornberger, and D. J. Wingham (2012), Subglacial melt channels and fracture in the floating part of Pine Island Glacier, Antarctica, J. Geophys. Res., 117, F03012, doi:10.1029/2012JF002360. 